\title{
Reasoning about Objects in a Natural History Museum: The Effect of Complexity of Questions on Object Labels
}

Anne M. Land-Zandstra, Kelly Hoefakker \& Welmoet Damsma

To cite this article: Anne M. Land-Zandstra, Kelly Hoefakker \& Welmoet Damsma (2020)

Reasoning about Objects in a Natural History Museum: The Effect of Complexity of Questions on Object Labels, Visitor Studies, 23:2, 218-236, DOI: 10.1080/10645578.2020.1781485

To link to this article: https://doi.org/10.1080/10645578.2020.1781485

电 Published online: 02 Jul 2020.

Submit your article to this journal $\widetilde{ }$

III Article views: 118

Q View related articles ¿

View Crossmark data ¿ 


\title{
Reasoning about Objects in a Natural History Museum: The Effect of Complexity of Questions on Object Labels
}

\author{
Anne M. Land-Zandstra ${ }^{a}$ (D) Kelly Hoefakker ${ }^{a}$, and Welmoet Damsma ${ }^{b}$ (D) \\ aDepartment of Science Communication \& Society, Leiden University, The Netherlands; \\ beducation Department, Naturalis Biodiversity Center, Leiden, The Netherlands
}

\begin{abstract}
In natural history museums, a large part of the educational mission is to facilitate family learning with and about objects. Questions on object labels can play a role in this learning process. In the current study, we investigated the effect that different types of questions on object labels can have on the reasoning conversations among family members. We audio-recorded family conversations at an exhibit that included a fossilized dinosaur egg and a text label containing a question. Sixty-six families participated in three conditions differing in the level of complexity of the question on the label. We found that a question of moderate complexity facilitated the longest conversations, with the largest number of complex inferences, compared to the simpler and the more complex question. When reasoning, families most often used evidence from prior knowledge and other parts of the exhibition, but did not often relate to personal experiences. During the longer and more complex conversations, parents took up a larger role in the conversation, facilitating their family's reasoning process. We suggest that open-ended, moderately complex questions on labels can facilitate family reasoning conversations. Providing enough context within the surrounding exhibits and connecting to prior knowledge may help the reasoning process.
\end{abstract}

\section{Introduction}

In a time in which internet and virtual reality are providing information and experiences at everyone's fingertips, museums in general and science museums in particular still have a unique position because they provide real objects (Dillon et al., 2016). Over the years, science museums have evolved from cabinets of wonder, showing many different objects without much context, to educational institutions that want to provide learning experiences that teach, amaze, and change visitors (Friedman, 2007; Packer \& Ballantyne, 2002). For these educational goals, just showing objects is not sufficient. The learning process of visitors needs to be facilitated by supporting materials, such as object labels, images, video, audio, or interactives. In addition, social interaction supports the learning process as well (Vygotsky, 1978). This social learning process happens through conversations among visitors or with museum staff. Conversations are both an instrument for and a demonstration of learning (Hohenstein \& Tran, 2007). Visitors 
may learn more when they talk with each other about what they see or experience (Allen, 2002; Crowley et al., 2001). Simultaneously, the content of conversations can be an indication of what is learned in museums (Hohenstein \& Moussouri, 2018). In family learning conversations, parents play a key role in the learning process of their children (Gleason \& Schauble, 1999; Rogoff, 2003; Zimmerman et al., 2008). Exhibit labels could provide a means to facilitate this learning process of parents and children. Previous studies have looked at exhibit labels and family conversations related to interactive exhibits (Allen, 2002; Horn et al., 2016). However, few studies have focused on how text labels may support the interaction and conversations around authentic objects (e.g. Hohenstein \& Tran, 2007; Serrell, 2015). In the current study we examined in what way questions on labels with a natural history object could facilitate reasoning in conversations between parents and children.

\section{Theoretical framework}

\section{Science learning in museums}

Learning in (science) museums is often studied from a social constructivism perspective (Hein, 1998; Hohenstein \& Moussouri, 2018), stemming from the work of Vygotsky (1978). Such studies look at learning in museums as a social process where knowledge and understanding is co-constructed among group members (Hohenstein \& Moussouri, 2018). This makes sense because in many science museums, people visit within (family) groups and interact with each other and with the museum objects and exhibits during their visit, while learning together. For example, Horn et al. (2016) found that social interaction during exhibit engagement had a positive impact on learning about evolution. Falk and Dierking (2000) propose in their Contextual Model of Learning that learning in museums is complex and is impacted by several contexts of the visitor and the museum itself. Learning is a combination of a process that happens within a person and input from outside (e.g. other visitors, the exhibits, events happening, conversations, other experiences from the past).

In addition, within museum education, learning is often considered in a broader sense than just the acquisition of new information (Kisiel et al., 2012; National Research Council, 2009; Rowe, 2002). Learning in museums is often considered to include more affective outcomes such as creativity and interest as well as acquiring skills such as being able to ask researchable questions or reasoning with evidence (National Research Council, 2009). In this study, we focus on reasoning, since it is an important aspect of scientific thinking and scientific literacy (Kisiel et al., 2012).

\section{Reasoning}

Scientific reasoning is a significant aspect of science literacy, especially reasoning with evidence. It includes asking questions, forming hypotheses, collecting evidence, making inferences, and revising theories (Crowley et al., 2001; Kisiel et al., 2012). Kisiel et al. (2012) define reasoning as the "gathering and use of evidence for thinking and communicating about thinking”. Zimmerman (2000) mentioned in her review of the development of scientific reasoning skills that participants used their prior experiences and 
conceptual knowledge if a scientific reasoning task contained a question or a problem. The knowledge of and the comparison with a prior situation was then used as evidence in reasoning. Gillies and Khan (2009) argued that teaching children to ask and answer questions is important to engage children in argumentation, problem-solving and learning in general.

Previous studies have looked at scientific reasoning in informal science education (Allen, 2002; Ash, 2003; Gutwill \& Allen, 2009; Kisiel et al., 2012). For example, Gutwill and Allen (2009) looked at how a specific intervention can increase the reasoning behavior of visitors. Other studies such as the ones by Ash (2003) and Allen (2002), focused on what reasoning looked like in family conversations.

\section{Family conversations in museums}

Within a social constructivism perspective of learning, conversations play an important role. Conversations can both be part of the process of learning as well as the outcome of learning (Leinhardt et al., 2002). As visitors interact with each other, their conversations are part of the learning process where they try to make sense of what they see. At the same time, listening to their conversations may be a way to gauge what they have learned during their visit. As such, visitor conversations have become part of the study of learning in museums.

Allen (2002) and Crowley et al. (2001) argued that scientific reasoning and science literacy development will be supported by family conversations in informal learning settings. Since parents know their children, they can provide links with previous knowledge and experience.

Parents can play different roles in family learning conversations. Firstly, parents can take the role of explainer or idea-suggester (Gleason \& Schauble, 1999; Rogoff, 2003). This can support the short-term learning of their child (Zimmerman et al., 2008). Rogoff (2003) called this process guided participation, which means that children can participate in science guided by their parents. Secondly, Bell et al. (2006) suggested that parents can act as bridges from children's prior experiences to their expertise development in science, technology, engineering and mathematics (STEM). The facilitation by parents includes the ability to remind their children of prior experiences. These familiar experiences can be used to explain or define new observations (McClain \& Zimmerman, 2014). Storytelling, by both children and parents, can also help to connect to and share prior experiences and knowledge in the learning process (Goodwin, 2007). Thirdly, focusing attention on important aspects and details of an object by parents supports children's understanding (Ornstein et al., 2004). Fourthly, similarity comparison of the unfamiliar object to familiar information can also support meaning-making of that object. The cognitive tool of similarity comparison may increase children's conceptual development (Valle \& Callanan, 2006). Finally, Ash (2003) showed that parents use a variety of inquiry skills, such as observing, questioning, hypothesizing, explaining and interpreting, when they talk with their children. Since children may take over the behavior of their parents, they can learn many scientific skills by the conversations with their parents. 
With regard to scientific reasoning in family conversations, Crowley et al. (2001) showed that children's exploration of evidence was observed longer, broader and more focused on comparisons when they engaged with an exhibit with their parents than without their parents. The researchers saw that parents talked about evidence identification, generation and interpretation to their children, which may help children to select relevant evidence. In some cases, parents took the role of explainer. In addition, parents helped children to build explanations about science during informal science activities. All of these strategies invite children to engage in scientific reasoning and to develop the habits of scientific literacy (Crowley et al., 2001).

\section{Object labels}

In this study, we look at reasoning in family conversations regarding an authentic object in a natural history museum. Although traditionally, museum objects were considered to "speak for themselves", that assumption may not be true (Evans et al., 2002). Visitors may look beyond just the appearance of an object and also consider its history and story (Van Gerven et al., 2018). As Evans et al. (2002) point out, the context in which objects are presented may impact the "voice that is being heard" by the visitor. In addition, context, including object labels, can influence the interaction with museum objects. Information on object labels, can support family conversations. Rand (2010) found that parents read out loud the labels to their children. This could be a start of a conversation about the object, because parents focus the attention of their children to the information on the label (the third category mentioned above). Moreover, Atkins et al. (2009) suggested that parents explained more to their children in the presence of object labels than without. Visitors utilized the authority of the science museum by reading the labels to confirm their emerging scientific claims during a conversation (McClain \& Zimmerman, 2014; Zimmerman et al., 2010). Hohenstein and Tran (2007) argued that guiding questions as part of the label text at object-based exhibits might stimulate inquiry and reflection in conversations. They found that exhibit labels with simplified text and one question, and exhibit labels with a guided question led to a dialogue with more open-ended questions. In addition, labels with a guided question led more often to explanations than labels with a simplified text (Hohenstein \& Tran, 2007). However, their results were ambiguous between different exhibits.

\section{Questions on object labels}

Earlier studies suggested that questions on object labels in museums can stimulate meaningful conversations (Gutwill, 2006; Hohenstein \& Tran, 2007). Haden et al. (2014) argued that question-asking and answering is important to stimulate understanding and learning of a scientific problem. However, the formulation of questions on the label might influence the conversation's content. Fivush et al. (2006) focused on open-ended questions and concluded that asking open-ended questions invited children to actively participate in the conversation. Openended questions often start with Who, What, Where or How (Fivush et al., 2006; Haden, 2010; Jant et al., 2014). These open-ended questions invite people to go beyond listing facts or naming objects, to conversations involving making meaning of what they observe. Haden 
et al. (2014) concluded that open-ended questions were more cognitively challenging than closed-ended questions, because they invited children to generate their own explanations.

Rand (2010) described five types of questions that fostered interactivity and family learning: 1) attention-focusing questions and measuring or counting questions, 2) comparison questions, 3) action questions, 4) problem-posing questions, 5) reasoning questions. As discussed above, in our study we selected reasoning questions to investigate if such questions would indeed ignite reasoning conversations.

\section{Current study}

In order to examine the effect of reasoning questions on object labels on family conversations, the current study analyzed spontaneous family conversations in a Dutch natural history museum. Our research question was formulated as follows: What is the effect of open-ended questions with different levels of complexity on the reasoning within family conversations in a natural history museum?

We addressed several subquestions:

- What is the effect of questions with different levels of complexity on the length of the conversations?

- What type of talk do families adopt (i.e. simple or complex inferences)?

- What type of evidence do families use (e.g. focus on comparisons or broadening content)?

\section{Methods}

\section{Research setting}

Naturalis Biodiversity Center in Leiden, the Netherlands, is a natural history museum that aims at encouraging curiosity and scientific literacy related to the natural world. Our study was performed during the exhibition T.rex in Town (2016-2017), centering around the display of a real T.rex skeleton. In order to investigate the impact of labels on family conversations, we selected a fossil of a dinosaur egg as the object of study, because it was an object that linked to the topic of the exhibition, and could speak to children's imagination. Furthermore, the shape and size could play a role in the conversations, giving starting points for reasoning. The object was placed by itself on a table in the same hall as the real T.rex skeleton (see Figure 1). An audio recorder was set up behind the table to record the conversations. One of the researchers was present in the exhibition hall to unobtrusively observe the families.

\section{Object labels}

We designed object labels with only one question to decrease distraction. We did not provide the answer in order to be able to focus on the impact of the question alone. In addition, even scientists are not sure about the answers to these questions. The text on the labels was limited, so that families did not stop reading because the text was too long. The questions for each condition were: 


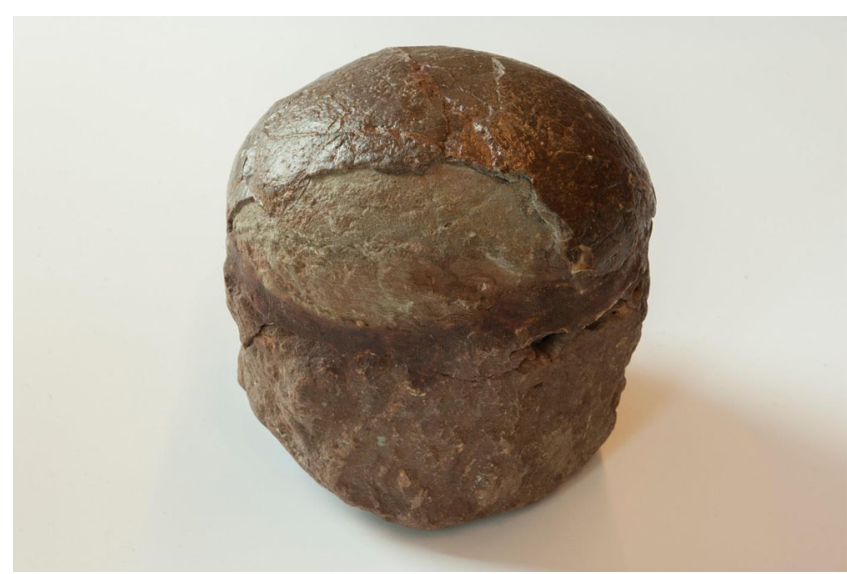

Figure 1. The dinosaur egg that was used in the experiment.

- Condition A. 'What does this look like?'

- Condition B. 'This is a REAL dinosaur egg. How big do you think the mother of this dinosaur egg was?'

- Condition C. 'This is a REAL dinosaur egg. What would the breeding place of a dinosaur have looked like?'

The questions differed in the level of complexity and the amount of reasoning that was needed to answer it. The first condition served as a control (no reasoning needed); the second condition needed a little bit of reasoning (comparing the T.rex with familiar animals and egg sizes); and the third condition needed more reasoning (comparing with other animals and reasoning about living environments) and possibly also more background knowledge about these living environments. The message that the object is a real object was included in the last two conditions to prevent the conversations from only focusing on the realness of the objects rather than on the question itself.

\section{Participants}

Since families are the main visitor group of the museum, we targeted families as participants for this study. In order to not introduce any experiment bias, we randomly recruited 118 families at the entrance of the museum. Families were defined as at least one adult with at least one child in the age of primary school (4-12 years). They could include older children as well. Only Dutch-speaking families were included in the study. Whenever a family that seemed to include children of the right age group approached the entrance of the museum they were asked to participate in the study. Families were asked to participate in the research study and were told that they would be recorded at some point in the exhibition, but no other information was given to make sure that they would not act differently because they were part of a study. The exhibit under study was located around half way through the exhibition. After one of the adults gave written consent, participating families were identified by a sticker on their clothing so that the researcher could observe them during the conversations at the research set up and could identify which audio recordings to include in the study. Not all families 
Table 1. Demographics and group size across conditions.

\begin{tabular}{lcccc}
\hline & A & B & C & Total \\
\hline \% female adult & $53.3 \%$ & $59.4 \%$ & $64.7 \%$ & $59.4 \%$ \\
$\%$ female child & $42.5 \%$ & $38.6 \%$ & $34.8 \%$ & $38.5 \%$ \\
Mean age children & 8.5 & 8.6 & 8.6 & 8.6 \\
Mean group size & 3.0 & 3.5 & 3.6 & 3.4 \\
\hline
\end{tabular}

Note. Condition A: What does it look like? Condition B: How big was the mother? Condition C: What would the breeding ground look like?

interacted with the exhibit under study, so we were able to record conversations of 66 families, evenly spread out over the three research conditions (23 in condition A, 21 in condition B, 22 in condition $\mathrm{C}$ ).

On average families consisted of 3.4 group members (range $2-8$ ). In all three conditions, group sizes were similar $(3.0,3.5,3.6$ respectively). Of all participating children, $62 \%$ ( 82 children) were boys and $38 \%$ (50 children) were girls. Of the parents who gave permission for their family, 35\% (24 adults) were male and 65\% (44 adults) were female. Some families included more than one adult, but we only collected information from the consenting adult. The age range of the children was $4-15$ years old, with an average of 8.6 years old. Table 1 shows that these family characteristics were similar across the three conditions. Because we recorded spontaneously occurring conversations, not all families were complete during the recorded conversation. Generally, recorded conversations included two to four members of the family. The majority of conversations included at least one adult and one child.

\section{Data analysis}

The recorded conversations were transcribed and coded. We coded for length of conversation (unit of analysis: conversation, starting when the first person of a family started to talk and ending when the family walked away from the exhibit; measured in seconds), portion of the conversation by parents versus children (unit of analysis: conversation; measured in number of words), and content of the conversation (unit of analysis: fragments). Two common approaches for analyzing content of conversations are content analysis and discourse analysis. Herrera and Braumoeller (2004) describe that although the two approaches come from different philosophical backgrounds, there are many similarities and overlaps. Because we were interested in the content of the conversation (evidence and content of reasoning) and not so much the way language was being used, and because we were using a mostly top-down coding scheme, we decided to implement a content analysis approach. However, we did incorporate some characteristics usually assigned to discourse analysis (studying conversations and not written texts, focusing on the meaning of text and not just counting words).

For the content analysis we divided the transcript up in fragments that contained one statement or one inference. Sometimes an inference could be an exchange among several members of the conversation developing one argument. To analyze the content of the conversation we adapted the codebook of Allen (2002). She developed a framework to investigate learning conversations in museums. The framework consists of five types of talk. Perceptual talk are all statements meant to draw attention to an element of the exhibition, e.g. pointing at it, naming it, or reading the text label aloud. Conceptual talk 
refers to cognitive interpretations such as reasoning, inferring, predicting. Two types of inferences were distinguished: simple and complex inferences. Simple inferences are "single interpretative statements of interpretation", often based on an observation or prior knowledge. Examples of simple inferences are: "It's an egg", "It looks like a rock". Complex inferences go beyond simple interpretations and contain a hypothesis, generalization or comparison. Examples of complex inferences are: "I think there is a real dino inside" or "But in those times there were different eggs". Connecting talk is talk that connects the exhibit to some other knowledge or experience, inside or outside of the museum. Connecting talk could connect to another exhibit (inter-exhibit connecting talk; IECT), to visitors' personal lives (life connecting talk; LCT) or to prior knowledge (knowledge connecting talk; KCT). Strategic talk referred to how to interact with the exhibit (adapted to mean how to interact with an object-based exhibit instead of an interactive exhibit). Affective talk were all utterances that conveyed some sort of emotion. Because we were interested in reasoning (gathering and use of evidence for thinking) in family conversations, we defined simple and complex inferences as reasoning and used connecting talk to identify which evidence families were using within their reasoning conversation. Therefore we double coded each inference with a label for the type of inference (single or complex) as well as the type of connection (inter-exhibit, life, or knowledge). Appendix A contains the codebook.

Intercoder reliability was tested by having a second coder code $29 \%$ of the data. Cohen's kappa was determined at 0.72 which indicates a satisfactory reliability. The conversations were transcribed, coded and analyzed in Dutch. We translated relevant quotes to English for this article. In order to investigate differences among the three conditions we performed some statistical analyses where appropriate. The number of conversations in each condition was not large enough to perform a statistical comparison of average holding time in each condition (as determined by a power analysis), but we did perform chi square tests to determine significant differences in number of words spoken by parents versus children, and number of simple versus complex inferences. We inspected standardized residuals to determine which comparisons were significantly different from the expected values.

\section{Results}

\section{General analysis}

Although they were not specifically prompted to read the label, all participating families that had a conversation at the exhibit under study referred to the information or question on the label. In condition A ('What does this look like?'), 20 out of 23 families (87\%) read the label out loud and 22 families (96\%) tried to answer the question. In condition B ('This is a REAL dinosaur egg. How big do you think the mother of this egg was?'), 18 out of 21 families (86\%) read the label out loud, but only 15 families (71\%) actually discussed the question. In condition C ('This is a REAL dinosaur egg. What would the breeding place of a dinosaur have looked like?') only 9 out of 22 families (41\%) read the label out loud and only 5 families (23\%) tried to answer the question.

Figure 2 shows the length of the family conversations for each condition. Overall, most conversations stopped after 60 seconds. In condition A (What does this look like?) the average holding time was 45 seconds (range: 9-127s). The average holding time in condition B (How big was the mother?) was 52 seconds (range: 19-148s). In condition $\mathrm{C}$ (What does the breeding place look like?) the average holding time was 45 seconds 


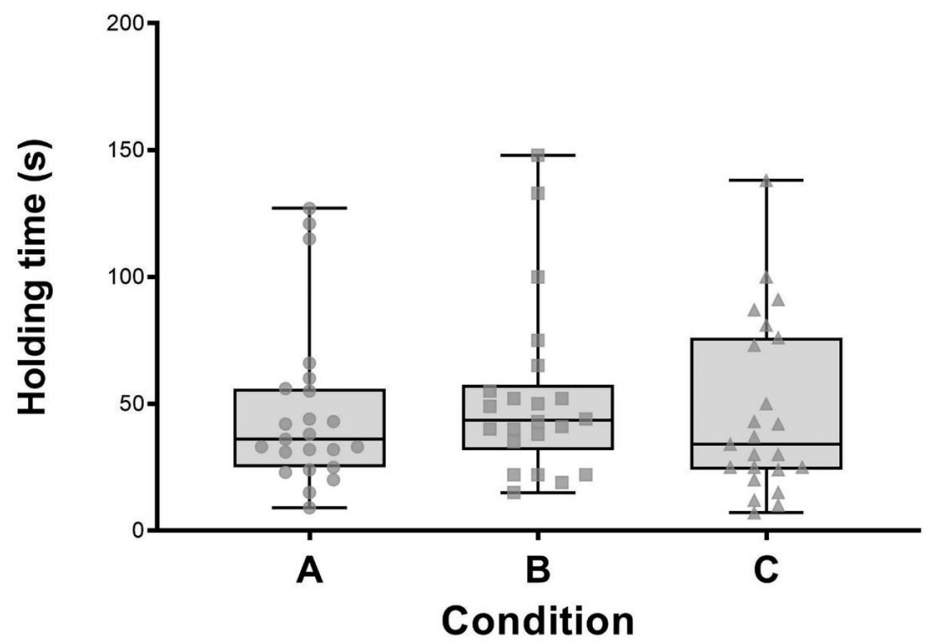

Figure 2. Boxplots of conversation time (s) for each condition. A: "What does it look like?" $(M=46.7 \mathrm{~s})$. B: "How big was the mother?" ( $M=52.7 \mathrm{~s})$. C: "What would the breeding ground look like?" $(M=47.0 \mathrm{~s})$.

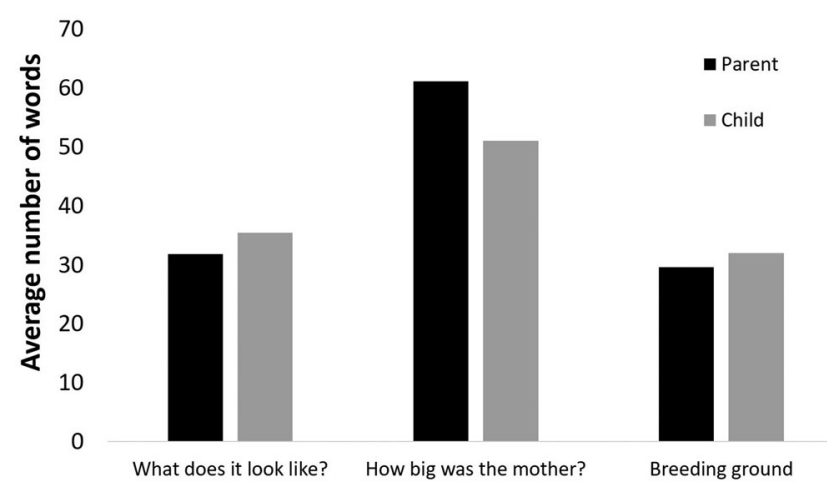

Figure 3. Average number of words uttered by parents and children per conversation for each condition.

(range: 7-138s). Since families in condition B had longer conversations, they used more words on average $(M=117$; range: $12-440)$ than in condition $\mathrm{A}(M=68$; range 11-249) and $C(M=64$; range 5-175). Because of the number of families in each condition, no statistical tests were performed to determine if these differences were significant. A Chi square test on the number of words spoken by children versus parents in each condition showed that in condition $B$, children spoke significantly less while parents spoke more than would be expected based on the entire sample $\left(\chi^{2}(2,5261)=24.4, p<.05\right)$. Figure 3 shows the number of words for each condition.

\section{Content analysis}

All conversations were coded for the type of talk that was used. Almost all conversations included some kind of perceptual talk (i.e. directing attention; 97\%), conceptual 
Table 2. Content of conversations.

\begin{tabular}{lcc}
\hline & Percentage of conversations (\%) & Average number of utterances per conversation \\
\hline Perceptual talk & 97.0 & 3.1 \\
Conceptual talk & 95.5 & 5.4 \\
Connecting talk & 86.4 & 3.6 \\
Strategic talk & 56.1 & 1.5 \\
Affective talk & 12.1 & 0.2 \\
\hline
\end{tabular}

talk (i.e. cognitive interpretations; 95.5\%) and connecting talk (i.e. connection to knowledge/experience; $86.4 \%$ ), see Table 2. Strategic talk (i.e. on how to interact with the exhibit; 56.1\%) and affective talk (i.e. emotions; $12.1 \%$ ) were less present in the conversations. Another way of looking at the type of talk is by looking at the average number of utterances per conversation, to see how prevalent each type of talk was throughout the conversations. This analysis showed that conceptual talk $(M=5.4$ utterances) was the most prevalent, followed by connecting talk $(M=3.6)$ and perceptual talk $(M=3.1)$. Again, strategic talk and affective talk were rare $(M=1.5$ and $M=0.2$, respectively).

Conceptual and connecting talk were most relevant to our research questions about reasoning, therefore they will be elaborated on below.

\section{Type of reasoning}

Within the conceptual talk we determined the type of reasoning in each conversation by distinguishing between simple inferences (SI) and complex inferences (CI). An example of a SI uttered by a child in this study is: "It looks like the brain of a T.Rex" (A21, c; child from family 21 in condition A), because the child made the assumption that the object must be part of the T.rex skeleton, but no second reasoning step was taken. We also considered statements like "brains", "eyeballs", “cranium” or "dung" SI because these statements must be based on recognizing features, shapes, size and color of something familiar, even if the reasoning was not explicitly part of the conversation. An example of a complex inference is: "Is there a dinosaur left inside then?" $(\mathrm{C} 12, \mathrm{c})$. This question includes a CI, because it was about the concepts related to the object. Knowledge about eggs (there should be something in it), is used to come to this question. This reasoning step made it a CI. Other examples of complex inferences are: "But do you think it would have such a nest, like a bird, in a tree?" (C3, p) and "It [dino poop] is not from this one [the T.rex], because it is not that big." (A15, c)

Figure 4 shows the average number of inferences per conversation for each condition. The number of simple inferences per conversation was highest in condition $\mathrm{A}(M=3,3$ SI per conversation) followed by condition $\mathrm{B}(M=1,0)$ and $\mathrm{C}(M=0,9)$. In contrast, complex inferences were most prevalent in condition $\mathrm{B}(M=2,4 \mathrm{CI}$ per conversation) followed by condition $\mathrm{C}(M=0,9)$ and condition A $(M=0,5)$. Chi square tests showed that in condition $\mathrm{A}$, there were more simple inferences and less complex inferences than could be expected based on the entire sample, while in condition B there were more complex inferences and less simple inferences $\left(\chi^{2}(2,196)=56.3, p<.001\right)$. Condition $\mathrm{C}$ did not show a significantly different amount of simple or complex inferences compared to the entire sample. 


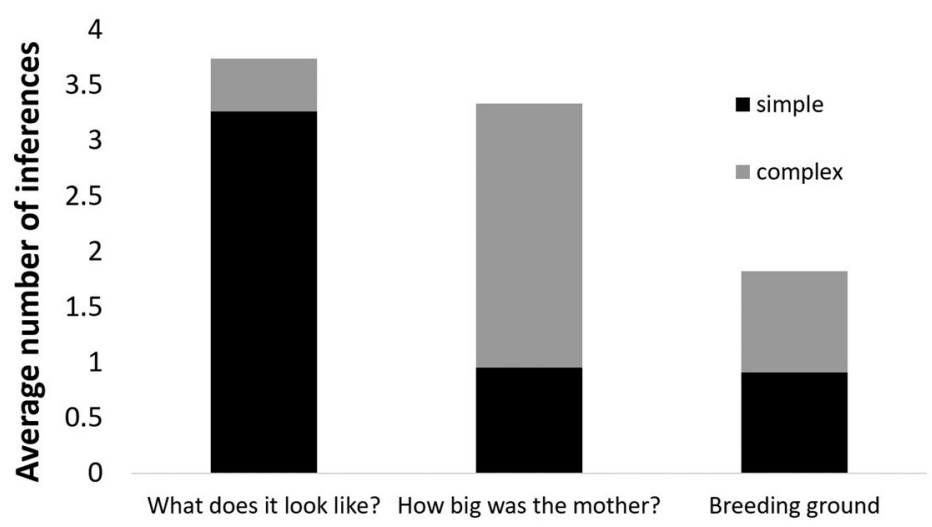

Figure 4. Average number of simple inferences $(\mathrm{SI})$ and complex inferences $(\mathrm{Cl})$ per conversation for each condition.

\section{Evidence in reasoning}

For each inference, we analyzed what type of evidence was used. We distinguished knowledge connecting talk (KCT), inter-exhibit connecting talk (IECT) and life connecting talk (LCT). Below is an example of a complex inference with knowledge connection. The quote suggested that the boy knows that fossils often will be glued.

Boy: "But it does not hatch anymore"

Mother: "No"

B: "Because it is glued" (B26)

Another conversation shows an example of inter-exhibit connection talk. In this conversations in condition $\mathrm{A}$, a mother and a daughter discussed what the object could be. The girl suggested that the object would be a fracture of the T.rex ribs which they could see behind them.

Girl: "Yeah I know it! Such a bump."

Mother: "A bump of which?"

G: "Of uhm. The ribs things or something..."

M: "Where the ribs are broken do you mean?"

G: "Yes, those bump."

M: "Don't you think that is a very big bump if you look at the ribs? Seems a bit too big to me."

G: "Yes, but look how big he is!"

M: "Yes, he is very big." (A40)

Finally, an example of an inference with life connecting talk is shown below where a grandmother talks about something she had seen somewhere else. Only the statements where a specific life situation is mentioned were labeled as life-connecting. 


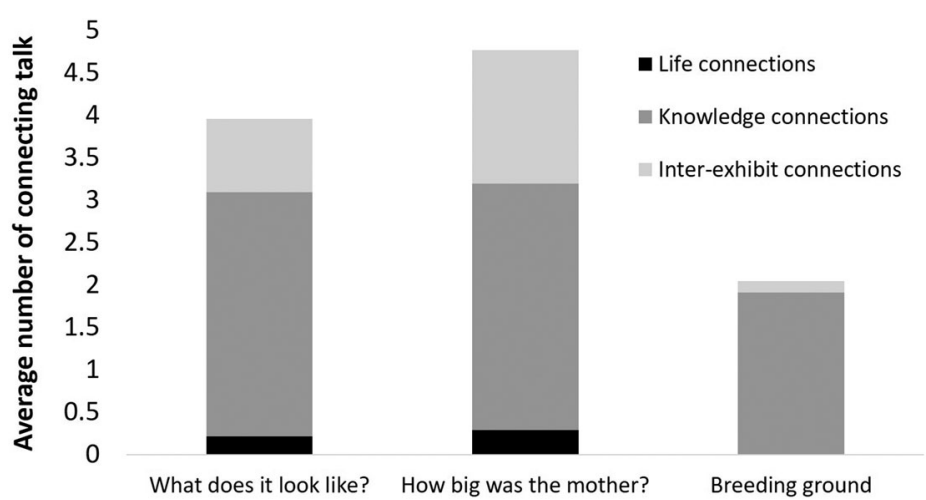

Figure 5. Average number of connecting talk per conversation in each condition, separated in life connections, knowledge connections, and inter-exhibit connections.

GM: "Should it be as big as an ostrich? Yes, I saw that in Aruba. But I had the idea that they were bigger..." (B11)

Figure 5 shows the number instances of connecting talk within each condition. Knowledge connection was the most common connecting talk used during this study (72\% of all connections), followed by inter-exhibit connection (24\%) and life connections (5\%). Conversations in condition B contained the most instances of connecting talk $(M=4.8$ per conversation), followed by condition $\mathrm{A}(M=4.0)$ and condition $\mathrm{C}(M=2.0)$.

\section{Discussion}

In this study, we investigated the effect of reasoning questions on family conversations in a natural history museum. In particular, we provided object labels in three different conditions with varying levels of reasoning and background knowledge needed to answer the question. We then looked at the reasoning in the family conversations at the exhibit. In condition A, the label read "What does this look like?"; in condition B it read: "This is a REAL dinosaur egg. How big do you think the mother of this egg was?; and in condition $\mathrm{C}$ it read: "This is a REAL dinosaur egg. What would the breeding place of a dinosaur have looked like?"

\section{Conversation characteristics}

Many of the families in our study who stopped at the dinosaur egg exhibit and had conversations about the object read the label out loud, supporting Rand's (2010) suggestion that parents use labels in the interaction with their children. More than half of the families in our study actually tried to answer the question. In condition B (about the mother of the egg), we heard the longest conversations, and parents talked more than their children compared to the other two conditions. These outcomes suggest that condition A was a question that could be solved with a short answer without a lot of support from a parent. Condition $B$ was complex enough to trigger parents and children to 
engage in longer and more complex conversations. Condition $\mathrm{C}$ may have been too complex to trigger parents to facilitate a conversation, as we discuss below.

\section{Content of conversations}

When looking at the type of talk in the family conversations, conceptual, connecting and perceptual talk were most prevalent, meaning that people talked most about cognitive interpretations, connections to prior knowledge or experiences and directing attention. Talk about emotional reactions (affective talk) and about interaction with an exhibit (strategic talk) were rare. It is difficult to compare these percentages to the original study by Allen (2002), because the situations are very different (complete exhibition vs. one exhibit; percentage of stops vs. percentage of utterances or conversations; interactive exhibits vs. object-based exhibit, making strategic talk less relevant). However, one clear difference is the low prevalence of affective talk in our study compared to Allen's, where affective talk was the second most heard talk. In addition, in Allen's study connecting talk was less common than in our study. Possibly, the fact that we specifically invited people to start reasoning about the provided question, resulted in more talk that connected to prior knowledge compared with the spontaneous conversations in Allen's study. Coupled with the fact that we heard most of the people reading the question and trying to answer it, this suggests that the questions on the label were able to facilitate family conversations toward connecting to prior knowledge and experiences.

\section{Reasoning in conversations}

With regard to the reasoning that families conducted within their conversations we found that in condition A most inferences were simple inferences, in condition B most inferences were complex, and in condition $C$ both types of inferences were low. In condition $\mathrm{A}$, the question triggered comparison of the unfamiliar object to familiar information. This type of comparison can support meaning-making of the dinosaur egg (Valle \& Callanan, 2006). The comparisons that families made were all linked to the physical features and the shape of the object. In condition $\mathrm{B}$, where the label gave away what the object was, the number of simple inferences was lower than in condition $\mathrm{A}$. The question in condition $\mathrm{B}$ triggered more complex inferences where parents and children together reasoned about how big the mother of the dinosaur egg could have been. These complex inferences often included several consecutive statements, going back and forth between parents and children.

Although conversations were longer in condition $\mathrm{B}$, the total number of statements was lower than in condition $\mathrm{A}$, caused by the fact that complex inferences take a longer time to develop. In contrast to condition $\mathrm{A}$ and condition $\mathrm{B}$, in condition $\mathrm{C}$ the total number of inferences made by the families was much lower. We speculate that the chosen word 'breeding place' (in Dutch: "broedplaats") was too difficult to understand for children, or was not something that they themselves would wonder about. As Serrell (2015) points out, questions on labels work best when the questions are similar to what visitors ask spontaneously. Also, parents may have had more trouble imagining a 
dinosaur nest than imagining the mother of an egg. They also needed to have some prior knowledge about the living environments of dinosaurs, which may have been lacking among the participating adults. As Ash (2003) showed, parents often take the lead in reasoning and experimenting with their children. We expect that parents may be hesitant to start a reasoning conversation with their kids if they don't know beforehand to which answer they are headed or if they feel they lack background knowledge. Parents may need some help in starting conversations with their children when they do not know the answer themselves. Similarly, Shine and Acosta (2000) found that parents had a more educational goal in mind (teaching their children something), instead of engaging in pretend play with their children. The authors suggest that parents need specific guidance to engage in open-ended play with their children. The study of Jant et al. (2014) showed that parents who had been given cues on how to have conversations with their children about objects talked with their children in more elaborate ways.

\section{Connecting talk}

We also looked at what evidence families used in their reasoning, i.e. to what type of information they connected. In all three conditions, most connections were made with prior knowledge (knowledge connecting talk, KCT), followed by connections to other exhibits (inter-exhibit connecting talk, IECT) and only a few connections with experiences in visitors' personal lives (life connecting talk, LCT). Connections with prior knowledge often included links with familiar objects such as chicken, ostrich, other eggs, other nests or other types of knowledge that visitors had about dinosaurs and eggs (e.g. that eggs are often glued together to preserve them, that larger animals often have larger eggs). These outcomes suggest that it is important to know about prior knowledge and experiences of the audience, for example through front-end evaluations (Borun, 2002).

When family conversations included IECT, they used mostly the T.rex skeleton standing next to the object in their reasoning. Some families walked around the skeleton to find evidence for what the object could be or to compare the features of the object to the bones of the T.rex. This observation suggests that it is important to provide clues for reasoning nearby, so that visitors' can use evidence from surrounding exhibits in their reasoning conversations. Making sure that an exhibition has a clear overarching theme or storyline may help (Allen, 2002). Contrary to what other studies suggest (Allen, 2002; McClain \& Zimmerman, 2014), the participants in this study did not make many connections to their personal lives. Possibly, the type of object, the topic (an extinct animal) and the type of assignment (invitation to start reasoning) did not trigger many links to personal experiences.

\section{Limitations}

This study has some limitations that may have impacted the validity of the results. One limitation is the fact that there might be a bias in the type of families that agreed to participate in this study. In addition, even though we did not give away the exact purpose of the study, they knew they were going to be audiotaped at some point in the museum. This may have impacted their behavior. However, none of the recorded 
families noticed the microphone, and only a few families speculated that the dinosaur egg exhibit might be the research location. Another limitation were technical issues such as the crowdedness of the exhibit at some moments and the fact that sometimes the conversations continued outside of the range of the microphone, resulting in some missing data. Lastly, in order to be able to perform statistical analyses on holding time of the object and questions a larger sample per condition should have been included.

\section{Future research}

One of the avenues of future research is to perform similar studies with different types of objects. As discussed, we suspect that visitors may use different types of evidence for different types of objects (e.g. more connections to personal lives with more familiar objects). In addition, it would be interesting to find out more about what level of reasoning parents and children are able to reach on their own. It would be interesting to find out why parents are reluctant to start reasoning conversations with their children if they do not know the answer themselves. Lastly, investigations into the interaction between parents and children during these conversations are another possible topic for future research. What role does each of the conversation participants take and who takes the lead?

\section{Conclusion}

In this study we found that open-ended reasoning questions on a label accompanying a dinosaur fossil was able to facilitate reasoning conversations among families. The type of complexity of the question had an effect on the length and content of the conversations. The question with a moderate complexity ("How big do you think the mother of this dinosaur egg was?") seemed to trigger longer and more complex reasoning conversations than the simpler question ("What does this look like?") and the more complex question ("What would the breeding place of a dinosaur have looked like?"). Furthermore, during longer reasoning conversations, parents took up the role of facilitator, illustrated by the fact that their share of the conversation is larger than their children's. During their reasoning, family members connected mostly to prior knowledge and other parts of the exhibition and not so much to their personal lives. Our results suggest that in order to support family reasoning conversations, exhibits should include open-ended questions of a suitable complexity and should provide enough links or context within the surroundings of the exhibit for people to make connections to prior knowledge and other elements within the exhibition. Parents could be supported by giving them hints of where to start their reasoning.

\section{Acknowledgements}

We would like to thank Dylan van Gerven and Tim van Wessel for their help with this research and the manuscript. 


\section{Disclosure statement}

No potential conflict of interest was reported by the authors.

\section{ORCID}

Anne M. Land-Zandstra (ID http://orcid.org/0000-0002-7604-9092

Welmoet Damsma (D) http://orcid.org/0000-0002-5290-0663

\section{References}

Allen, S. (2002). Looking for learning in visitor talk: A methodological exploration. In G. Leinhardt, K. Crowley, \& K. Knutson (Eds.), Learning conversations in museums (pp. 259-303). Lawrence Erlbaum Associates.

Ash, D. (2003). Dialogic inquiry in life science conversations of family groups in a museum. Journal of Research in Science Teaching, 40(2), 138-162. https://doi.org/10.1002/ tea. 10069

Atkins, L. J., Velez, L., Goudy, D., \& Dunbar, K. N. (2009). The unintended effects of interactive objects and labels in the science museum. Science Education, 93(1), 161-184. https://doi.org/10.1002/sce.20291

Bell, P., Bricker, L. A., Lee, T. R., Reeve, S., \& Zimmerman, H. T. (2006). Understanding the cultural foundations of children's biological knowledge: Insights from everyday cognition research. In June 26-July 1 (Ed.) [Paper presentation]. International Conference of the Learning Sciences, Bloomington, IN.

Borun, M. (2002). Object-based learning and family groups. In S. G. Paris (Ed.), Perspectives of object-centered learning in museums (pp. 245-260). Lawrence Erlbaum Associates.

Crowley, K., Callanan, M. A., Jipson, J. L., Galco, J., Topping, K., \& Shrager, J. (2001). Shared scientific thinking in everyday parent-child activity. Science Education, 85(6), 712-732. https:// doi.org/10.1002/sce.1035

Crowley, K., Callanan, M. A., Tenenbaum, H. R., \& Allen, E. (2001). Parents explain more often to boys than to girls during shared scientific thinking. Psychological Science, 12(3), 258-261. https://doi.org/10.1111/1467-9280.00347

Dillon, J., DeWitt, J., Pegram, E., Irwin, B., Crowley, K., Haydon, R., King. H., Knutson, K., Veall, D., \& Xanthoudaki, M. (2016). A learning research agenda for natural history institutions. Natural History Museum.

Evans, E. M., Mull, M. S., \& Poling, D. A. (2002). The authentic object? A child's-eye view. In S. G. Paris (Ed.), Perspectives on object-centered learning in museums (pp. 55-77). Routledge.

Falk, J. H., \& Dierking, L. D. (2000). Learning from museums: Visitor experiences and the making of meaning. Altamira Press.

Fivush, R., Haden, C. A., \& Reese, E. (2006). Elaborating on elaborations: Role of maternal reminiscing style in cognitive and socioemotional development. Child Development, 77(6), 1568-1588. https://doi.org/10.1111/j.1467-8624.2006.00960.x

Friedman, A. J. (2007). The extraordinary growth of the science-technology museum. Curator: The Museum Journal, 50(1), 63-75. https://doi.org/10.1111/j.2151-6952.2007.tb00250.x

Gillies, R. M., \& Khan, A. (2009). Promoting reasoned argumentation, problem-solving and learning during small-group work. Cambridge Journal of Education, 39(1), 7-27. https://doi. org/10.1080/03057640802701945

Gleason, M. E., \& Schauble, L. (1999). Parents' assistance of their children's scientific reasoning. Cognition and Instruction, 17(4), 343-378. https://doi.org/10.1207/S1532690XCI1704_1

Goodwin, M. (2007). Occasioned knowledge exploration in family interaction. Discourse \& Society, 18(1), 93-110. https://doi.org/10.1177/0957926507069459

Gutwill, J. P. (2006). Labels for open-ended exhibits: Using questions and suggestions to motivate physical activity. Visitor Studies, 9(1), 109. 
Gutwill, J. P., \& Allen, S. (2009). Facilitating family group inquiry at science museum exhibits. Science Education, 94(4), 710-742. https://doi.org/10.1002/sce.20387

Haden, C. A. (2010). Talking about science in museums. Child Development Perspectives, 4(1), 62-67. https://doi.org/10.1111/j.1750-8606.2009.00119.x

Haden, C. A., Jant, E. A., Hoffman, P. C., Marcus, M., Geddes, J. R., \& Gaskins, S. (2014). Supporting family conversations and children's STEM learning in a children's museum. Early Childhood Research Quarterly, 29(3), 333-344. https://doi.org/10.1016/j.ecresq.2014.04.004

Hein, G. E. (1998). Learning in the museum. Routledge.

Herrera, Y. M., \& Braumoeller, B. F. (2004). Symposium: Discourse and content analysis. Qualitative Methods, 2(1), 15-19. Retrieved from https://wcfia.harvard.edu/files/wcfia/files/870_symposium.pdf

Hohenstein, J., \& Moussouri, T. (2018). Museum learning: Theory and research as tools for enhancing practice. Routledge.

Hohenstein, J., \& Tran, L. U. (2007). Use of questions in exhibit labels to generate explanatory conversation among science museum visitors. International Journal of Science Education, 29(12), 1557-1580. https://doi.org/10.1080/09500690701494068

Horn, M. S., Phillips, B. C., Evans, E. M., Block, F., Diamond, J., \& Shen, C. (2016). Visualizing biological data in museums: Visitor learning with an interactive tree of life exhibit. Journal of Research in Science Teaching, 53(6), 895-918. https://doi.org/10.1002/tea.21318

Jant, E. A., Haden, C. A., Uttal, D. H., \& Babcock, E. (2014). Conversation and object manipulation influence Children's Learning in a Museum. Child Development, 85(5), 2029-2045. https:// doi.org/10.1111/cdev.12252

Kisiel, J., Rowe, S., Vartabedian, M. A., \& Kopczak, C. (2012). Evidence for family engagement in scientific reasoning at interactive animal exhibits. Science Education, 96(6), 1047-1070. https:// doi.org/10.1002/sce.21036

Leinhardt, G., Crowley, K., \& Knutson, K. (Eds.). (2002). Learning conversations in museums. Lawrence Erlbaum Associates.

McClain, L. R., \& Zimmerman, H. T. (2014). Prior experiences shaping family science conversations at a nature center. Science Education, 98(6), 1009-1032. https://doi.org/10.1002/sce.21134

National Research Council. (2009). Learning Science in Informal Environments: People, Places, and Pursuits. Retrieved from http://books.google.com/books?hl=en\&lr=\&id=vdOIlY7WdJUC\&pgis=1

Ornstein, P. A., Haden, C. A., \& Hedrick, A. M. (2004). Learning to remember: Social-communicative exchanges and the development of children's memory skills. Developmental Review, 24(4), 374-395. https://doi.org/10.1016/j.dr.2004.08.004

Packer, J., \& Ballantyne, R. (2002). Motivational factors and the visitor experience: A comparison of three sites. Curator: The Museum Journal, 45(3), 183-198. https://doi.org/10.1111/j.21516952.2002.tb00055.x

Rand, J. (2010). Write and design with family in mind. In D. L. McRainey \& J. Russick (Eds.), Connecting kids to history with museum exhibitions (pp. 257-284). Routledge.

Rogoff, B. (2003). The cultural nature of human development. Oxford University Press.

Rowe, S. (2002). The role of objects in active, distributed meaning-making. In S. G. Paris (Ed.), Perspectives of object-centered learning in museums2 (pp. 19-35). Lawrence Erlbaum Associates.

Serrell, B. (2015). Exhibit labels: An interpretative approach (Second). Rowman \& Littlefield.

Shine, S., \& Acosta, T. Y. (2000). Parent-child social play in a children 's museum published by: national council on family relations stable URL: http://www.jstor.org/stable/585700 Linked references are available on JSTOR for this article: Parent-Child Social Play in a Children's Mu. Family Relations, 49(1), 45-52. https://doi.org/10.1111/j.1741-3729.2000.00045.x

Valle, A., \& Callanan, M. A. (2006). Similarity comparisons and relational analogies in parentchild conversations about science topics. Merrill-Palmer Quarterly, 52(1), 96-124. https://doi. org/10.1353/mpq.2006.0009

Van Gerven, D. J. J., Land-Zandstra, A. M., \& Damsma, W. (2018). Authenticity matters: Children look beyond appearances in their appreciation of museum objects. International Journal of Science Education, Part B, 8(4), 325-339. https://doi.org/10.1080/21548455.2018.1497218

Vygotsky, L. (1978). Mind in society: The development of higher psychological processes. Harvard University Press. 
Zimmerman, C. (2000). The development of scientific reasoning skills. Developmental Review, 20(1), 99-149. https://doi.org/10.1006/drev.1999.0497

Zimmerman, H. T., Perin, S., \& Bell, P. (2010). Parents, science and interest: The role of parents in the development of youths' interests. Museums \& Social Issues, 5(1), 67-86. https://doi.org/ 10.1179/msi.2010.5.1.67

Zimmerman, H. T., Reeve, S., \& Bell, P. (2008). Distributed expertise in a science center. Journal of Museum Education, 33(2), 143-152. https://doi.org/10.1080/10598650.2008.11510595

\section{About the authors}

Anne M. Land-Zandstra is an Assistant Professor in the Science Communication \& Society Department of Leiden University in the Netherlands. Her research focuses on authenticity in informal science education, including the role of real objects in science museums.

Kelly Hoefakker was a master's student in Life Science \& Technology and Science Communication \& Society at the time of this research study. She now works as a researcher at the Netherlands Cancer Institute.

Welmoet Damsma is a Learning Officer and trainer within the Educational Department of Naturalis Biodiversity Center. As such, she is responsible for research and evaluation and liaises with different researchers both inside and outside Naturalis. In addition, she develops and organizes professional development of Naturalis' educators. 


\section{Appendix A. Codebook Reasoning with Objects}

\begin{tabular}{|c|c|c|c|}
\hline Category & Code & Description & Typical excerpts \\
\hline \multirow[t]{4}{*}{ Perceptual talk } & Identification & $\begin{array}{l}\text { Pointing at an object, pointing } \\
\text { out something }\end{array}$ & $\begin{array}{l}\text { "Look what is lying here"; } \\
\text { "What is this?" }\end{array}$ \\
\hline & Naming & Giving an object a name. & $\begin{array}{l}\text { "Hey, a rock"; "It has a label"; } \\
\text { "a black tablecloth" }\end{array}$ \\
\hline & Feature & $\begin{array}{l}\text { Pointing out a specific aspect } \\
\text { or part }\end{array}$ & $\begin{array}{l}\text { "Do you see that bump?"; "See } \\
\text { those ridges" }\end{array}$ \\
\hline & Quotation & $\begin{array}{l}\text { Reading text aloud, referring } \\
\text { to label }\end{array}$ & $\begin{array}{l}\text { "What does it look like?"; "This } \\
\text { is a real dino egg" }\end{array}$ \\
\hline \multirow[t]{4}{*}{ Conceptual talk } & $\begin{array}{l}\text { Simple inference } \\
\text { (reasoning) }\end{array}$ & $\begin{array}{l}\text { A single interpretative statement } \\
\text { of interpretation of part of the } \\
\text { exhibit, based on an } \\
\text { observation. }\end{array}$ & $\begin{array}{l}\text { "It is an egg"; "This looks like } \\
\text { a rock" }\end{array}$ \\
\hline & $\begin{array}{l}\text { Complex inference } \\
\text { (reasoning) }\end{array}$ & $\begin{array}{l}\text { An explicit hypothesis, comparison, } \\
\text { relationship with knowledge. } \\
\text { Often using words like because, } \\
\text { therefore, so that, or implying } \\
\text { that those words should have } \\
\text { been part of the statement. }\end{array}$ & $\begin{array}{l}\text { "If ..., then ...."; "But in those } \\
\text { times there were different } \\
\text { eggs"; "I think there is a real } \\
\text { dino inside" }\end{array}$ \\
\hline & Prediction & $\begin{array}{l}\text { Stating an expectation on what } \\
\text { will happen next. }\end{array}$ & "Maybe a dino will still hedge" \\
\hline & Metacognition & $\begin{array}{l}\text { Reflection on own state of } \\
\text { knowledge; including correcting } \\
\text { someone else's response by } \\
\text { stating the 'correct' answer. }\end{array}$ & $\begin{array}{l}\text { "Oh, maybe not"; "I thought so, } \\
\text { too"; "I agree" }\end{array}$ \\
\hline \multirow[t]{3}{*}{ Connecting talk } & Life connection & $\begin{array}{l}\text { Story, personal association, } \\
\text { connection with something } \\
\text { familiar (e.g. their own body, } \\
\text { familiar animals) }\end{array}$ & $\begin{array}{l}\text { Stories about chicken at } \\
\text { grandparents, etc. }\end{array}$ \\
\hline & $\begin{array}{l}\text { Knowledge } \\
\text { connection }\end{array}$ & $\begin{array}{l}\text { Referring to prior knowledge from } \\
\text { before their visit to the } \\
\text { museum; including implicit } \\
\text { reference to prior knowledge by } \\
\text { just stating what they thought } \\
\text { the object was. }\end{array}$ & $\begin{array}{l}\text { "This is an egg"; "Female } \\
\text { dinosaurs are larger than } \\
\text { male ones"; "Dinosaur egg" }\end{array}$ \\
\hline & $\begin{array}{l}\text { Inter-exhibit } \\
\text { connection }\end{array}$ & $\begin{array}{l}\text { Link with other elements of the } \\
\text { exhibition, or the rest of } \\
\text { the museum }\end{array}$ & $\begin{array}{l}\text { "I think this belongs to Trix } \\
\text { [the T.rex fossil behind } \\
\text { them], otherwise it would } \\
\text { not be here."; "It could } \\
\text { belong to the one we } \\
\text { saw before" }\end{array}$ \\
\hline \multirow[t]{2}{*}{ Strategic talk } & Use & $\begin{array}{l}\text { Statement about how to use the } \\
\text { exhibit; talk about touching the } \\
\text { object or how to find } \\
\text { the answer }\end{array}$ & $\begin{array}{l}\text { "You are not supposed to } \\
\text { touch it"; "I wish I brought } \\
\text { my magnifying glass to look } \\
\text { at it from up close" }\end{array}$ \\
\hline & Metaperformance & Evaluation of performance & $\begin{array}{l}\text { "If you drop it, it will break"; } \\
\text { "Now it has our finger } \\
\text { prints"; "We won't find } \\
\text { the answer" }\end{array}$ \\
\hline \multirow[t]{3}{*}{ Affective talk } & Pleasure & Positive statements & "Cool"; "Beautiful" \\
\hline & Displeasure & Negative statements & "Boring" \\
\hline & Intrigue & $\begin{array}{l}\text { Showing amazement, surprise, } \\
\text { fascination }\end{array}$ & "Wow" \\
\hline
\end{tabular}

